\title{
Congestion management in Indian Power Transmission System
}

\author{
Qasim Khan ${ }^{1}$, Furkan Ahmad ${ }^{2}$, Mohd Imran ${ }^{3}$ \\ 1,2Department of Electrical Engineering, Aligarh Muslim University, Aligarh, India \\ 3Department of Computer Engineering, Aligarh Muslim University, Aligarh, India \\ 1 qasim.rs@amu.ac.in \\ 2 furkanahmad@zhcet.ac.in \\ ${ }^{3}$ mohd.imran@zhcet.ac.in
}

\begin{abstract}
Congestion, signify a crisis where limit of transmission capacity overflows than transmission network capabilities, resulting in a violation of network security limits, being thermal, voltage stability limits, or levelled crucial contingency condition. Power Distribution system comprises huge quantity of physical utilities and interconnected network make it vulnerable to congestion at any non-specific location. This paper presents the various methods to reduce the congestion in Indian power sector. Further, on the basis of limitation which has been indulge with the present scenario of power market some suggestion has been provided which may lead a convention grid to smart grid system.
\end{abstract}

Keyword - Congestion; Transmission Capacity; Congestion Management; Market splitting.

\section{INTRODUCTION}

Congestion, signify a crisis where limit of transmission capacity overflows than transmission network capabilities, resulting in a violation of network security limits, being thermal, voltage, stability limits, or levelled crucial contingency condition. Power Distribution system comprises huge quantity of physical utilities and interconnected network make it vulnerable to congestion at any non-specific location [1].

A vertically integrated utility structure have a centrally directed or controlled over generation, transmission, and distribution. The optimal dispatch solution implementing security constrained to attain least cost operation of the system limits the probability of congestion and regulate power flow limits on the transmission lines [2].

The Introduction of power market and conversion of monopoly to multi-seller/multi-buyer exchange via Electricity Act'2003 make it prone to congestion and lead to congestion management. In deregulated power environment, buyer only objective of getting cheapest seller creates the specific transmission corridor overloaded and unable to execute all transaction and hence, cause congestion [3].

Congestion can have cause as temporary bottlenecks which is resultant of outages for maintenance work, technical faults or particular market conditions and Structural bottlenecks are a resultant of the level of expansion of the grid and the localization of generation and consumption within the grid comes around longer periods of time or at regular intervals. Congestion management is a mechanism to prioritize the transactions and commit to such a schedule which would not overload the network. Despite these measures, congestion can still occur in real time following a forced outage of transmission line [4].

The system operator then handles this situation by means of real time congestion management. Congestion management methods based on identification of congestion cause, efficient and maximum usability as well stability of system with economic, transparency and competitive operation. This paper illustrate the congestion management methods briefly and the role of splitting mechanism in energy exchange with real time data and comments on its results.

\section{Page Layout}

\section{A. Generation at Glance}

Today, installed capacity stands at $302 \mathrm{GW}$, making India's the fifth-largest power system in the world after China, the United States, Japan, and the Russian Federation. Recent capacity addition, particularly in the 11th Five-Year Plan (2007-12) at 54 GW, has been the highest in the country's history, but even then, it was only 69 percent of the $78 \mathrm{GW}$ target set at the beginning of the plan period. The best implementation performance, by far, was in the 7th Plan, when 96 percent of the target was met. Figure 1 shows the total installed capacity in India, while Table 1 describes the total net peak availability and demand for the fiscal year 2015-16. It is observed the peak demand as well as peak availability were $167280 \mathrm{MW}$ and $160474 \mathrm{MW}$ in Sep [5]. 


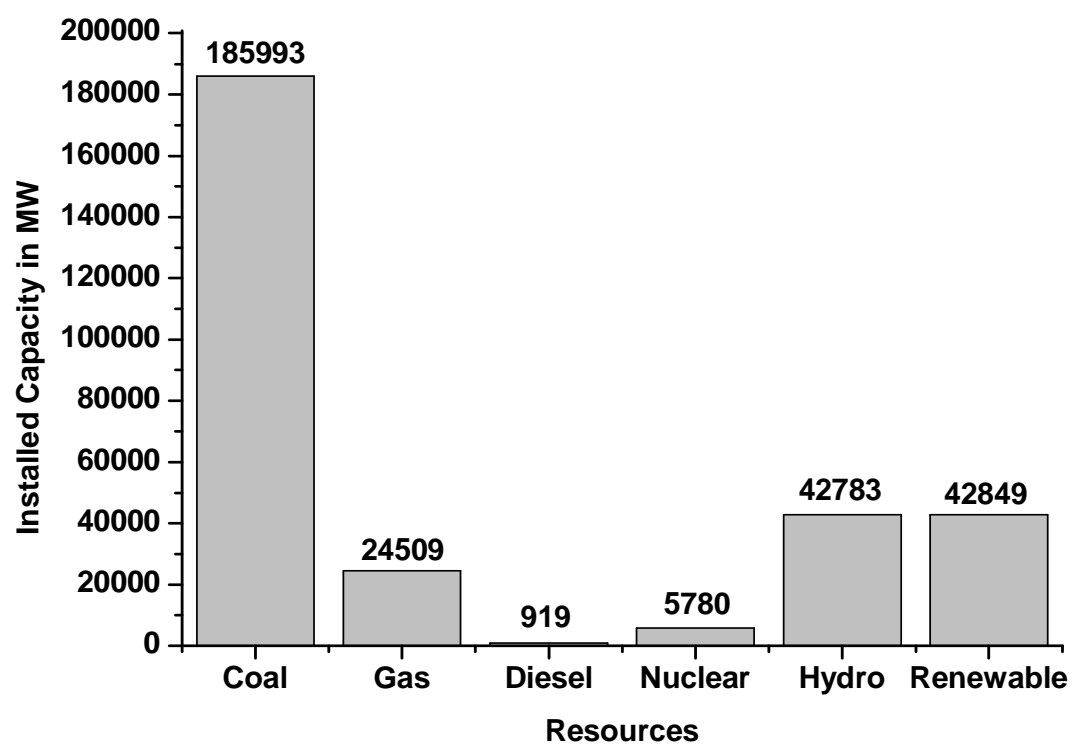

Fig. 1. Present scenario of energy infrastructure.

Table I. Peak Availability and Demand for the fiscal year 2015-16.

\begin{tabular}{|c|c|c|c|c|}
\hline All India & $\begin{array}{c}\text { Peak Demand } \\
\text { (MW) }\end{array}$ & $\begin{array}{c}\text { Peak Availability } \\
\text { (MW) }\end{array}$ & $\begin{array}{c}\text { Surplus(+)/ Deficit(-) } \\
\text { (MW) }\end{array}$ & \% \\
\hline Apr-15 & 149781 & 146576 & -3205 & -2.13 \\
\hline May-15 & 156089 & 151647 & -4442 & -2.84 \\
\hline Jun-15 & 159202 & 155159 & -4043 & -2.53 \\
\hline Jul-15 & 163377 & 158101 & -5276 & -3.22 \\
\hline Aug-15 & 163157 & 157266 & -5891 & -3.61 \\
\hline Sep-15 & 167280 & 160474 & -6806 & -4.06 \\
\hline Oct-15 & 164747 & 157549 & -7198 & -4.36 \\
\hline Nov-15 & 152023 & 149894 & -2129 & -1.40 \\
\hline Dec-15 & 151703 & 148348 & -3355 & -2.21 \\
\hline Jan-16 & 154843.502 & 151201.678 & -3641.824 & -2.35 \\
\hline Feb-16 & 155721.37 & 153206.52 & -2514.85 & -1.61 \\
\hline Mar-16 & 156640.079 & 154474.67 & -2165.409 & -1.38 \\
\hline
\end{tabular}

\section{B. Transmission infrastructure}

Transmission infrastructure is backbone for operation of a competitive electricity market. The Inter-State Transmission System, which is the integrating backbone of India's vast National Electricity Grid, has over the years achieved tremendous growth. There has been a marked increase in growth of central sector transmission system and transformation capacity during the 11th Plan and it is expected to increase during the 12th Plan as well. However, transmission congestion in some parts of the grid underlines the need for emphasis on development of adequate transmission system.

The Planning Commission estimates a power demand of $450 \mathrm{GW}$ and total installed capacity of about 600 GW by 2022 . To carry this demand, the national grid's transmission capacity would need to be gradually enhanced to about $150 \mathrm{GW}$ by 2022 (Planning Commission 2006). The target in the 12th Plan is to add $40 \mathrm{GW}$ in transmission capacity (Planning Commission 2013). Currently, $19 \mathrm{GW}$ is under construction-78 percent in the private sector. The below Table 1 describes the Inter Regional Transmission Capacity in India till Nov 2016 [6]. 
Table II. Font sizes of headings. Table captions should always be positioned above the tables.

\begin{tabular}{|c|c|c|c|c|c|c|c|c|c|}
\hline Break-up & $\begin{array}{c}\text { ER - } \\
\text { NR }\end{array}$ & $\begin{array}{l}\text { ER - } \\
\text { WR }\end{array}$ & $\begin{array}{c}\text { ER - } \\
\text { SR }\end{array}$ & $\begin{array}{l}\text { ER - } \\
\text { NER }\end{array}$ & $\begin{array}{l}\text { WR - } \\
\text { NR }\end{array}$ & $\begin{array}{c}\text { WR } \\
- \text { SR }\end{array}$ & $\begin{array}{l}\text { NR - } \\
\text { NER }\end{array}$ & $\begin{array}{c}\text { 132kV } \\
\text { (Inter } \\
\text { Regional) }\end{array}$ & $\begin{array}{l}\text { Grand } \\
\text { Total }\end{array}$ \\
\hline Up to Nov-16) & 19530 & 12790 & 3630 & 2860 & 12920 & 7920 & 3000 & 600 & $62650^{* *}$ \\
\hline
\end{tabular}

\section{III.CONGESTION MANAGEMENT METHODS}

The congestion management schemes are efficient transmission capacity allocation which strongly coupled with the overall market design. Thus, dissimilarity among these schemes can be made based on market based congestion management methods and other methods based on some criteria for allocation of transmission capacity. Market-based solutions to congestion are deemed fairer as they contribute better to economic efficiency than other methods and later methods are supposed to introduce some kind of arbitrariness as they do not contribute towards efficient pricing of congested link. The congestion method used all over world categories in two sub section as; non market method and market method which divided into sub-sections.

Capacity Allocation Methods, is one of the non-market method which utilize the idea of Access limitation for Specific owner, priority Queue, pro rata rationing with drawback such as origin of gaming and non-economic. Another non-market method is congestion alleviation methods which utilizes redispatching and countertrading with capability of decision making during congestion. With reference of market design, market methods implemented explicit auction giving advantages cross border capacity allocation while implicit auction with inseparable energy charges and transmission capacity charges.

\section{A. Conventional and Modernized congestion methods}

1) Nodal pricing method: The nodal costs shift as per the geographic areas, thusly giving them the name Locational Marginal Prices (LMP). The nodal costs prompt to generation of heavy surplus. This surplus is then used to pay the 'agreement rights'. An agreement right provides the correct holder the capacity to infuse power at one hub and remove it at another in the transmission network [7].

2) Uplift cost: Uplifts allude to security cost equivalent to the difference of the total cost of supply in constrained and unconstrained cases. The uplift cost incorporates transmission services uplift (the cost brought about because of the physical constraints of the system), energy uplift (the expenses of demand forecast error and generator deficits), reactive uplift (regulate the system voltage), unscheduled accessibility instalments (the capacity instalment paid to gensets that are accessible however are not required to run).

3) Price Area Congestion Management (PACM): PACM is extensively practiced in Nordic countries as well as in India. Basically, it is encouraged in bilateral, de-centralized, day ahead type markets. Each area consists of several generators and loads offering different bids [8].

4) Available Transfer Capability based congestion management: ATC refers to the "Available Transfer Capability". It is the measure of the extra power that could be transferred on the transmission line [9]

5) Flexible AC Transmission Systems (FACTS) devices: There are measures by which congestion could be regulates includes the cost free measure and the non-cost free measure. Former measures are more beneficial as they maintain a strategic distance from any kind of financial inconsistencies. It incorporate implementation of FACTS gadgets particularly thyristor controlled arrangement compensator (TCSC) and unified power flow controller (UPFC). FACTs devices can be grouped into three classes: series controller, shunt controller and combined series-shunt controller. The series controllers like thyristor controlled series compensator (TCSC), static synchronous series compensator (SSSC) and thyristor controlled phase-angle regulator (TCPAR) are utilized as a part of reducing line over-burdens and expanding exchange ability by controlling power flow. The shunt controllers, for example, SVC (static VAr compensator) and STATCOM (static synchronous compensator) can be utilized to remunerate voltages by infusing, directly or indirectly, reactive power at the low voltage buses. The joined series-shunt controllers, for example, UPFC can be utilized as a part of the system to discharge the power flow congestion and support voltage [10].

6) Optimization techniques and expert system: Congestion management is basically a non-linear program involving a lot of variables which could be solved using optimization algorithms. The most often used optimization techniques are categorized as Genetic Algorithm (GA), Particle Swarm Optimization (PSO), Bacterial Foraging Algorithm, Expert System Approach and a few other evolutionary strategies [7]. 


\section{B. Transfer Capability Network}

Congestion, as present in deregulated power scenario tends a transmission line touches its threshold limit. Transfer capability is significant and its design need Total transfer capability (reliable electric power transfer over interconnected network), Available Transfer Capability (commercially available power transfer over the network), Transmission Reliability Margin (standard margin in transfer capability for critical cases), and Credible Contingency [4]. There is dissimilarity between transfer capability and transmission capability on the basis of ' $\mathrm{N}-1$ ' criteria, Stability Criteria, Non-uniform loading of parallel lines, Loop flows, Voltage profile, Load generation disposition, Intra-state network configuration, and Law of diminishing returns. The capability and reliability of transmission networks may be influence by constraint including physical and electrical characteristics. The physical constraint is overheating of lines due to excess transfer of power over a long time. The electrical constraints comprises deregulated system voltage, system disturbance and frequency fluctuation that influence stability. A transmission corridor shall be considered congested overpassing of standardized grid voltage at nodes, real-time power flow along a corridor exceeds the corridor's ATC for 15-minute, or one or more transmission lines in the corridor are loaded beyond the operating limit [11]. In case of this alarming stage, NLDC/SLDC may issue a warning notice to all the Regional entities to observe the congestion within its region.

\section{IV.CONGESTION MANAGEMENT IN ENERGY BAZAAR}

The electricity Acts 2003 has mold power market of India from monopoly in each power section to Efficient, open and complete competitive markets with buyer and seller with maximum transparency. Transmission congestion acts as hindrance for growing energy market [12].

Congestion as network constraints on dispatch and it interferes with the market's merit dispatch objective of meeting demand at the lowest possible cost. Congestion cost is limited to participants at exchanges and favor on bilateral users in existing market splitting method at exchanges, which strongly discourage and influence the bids. Power exchanges are advantageous from bilateral and OTC markets in price discovery. The minimum cost electricity for customer by generation unit may not be possible during congestion and arise to higher cost for dispatch. This introduce risk for the market, which consequently affects bidding, dispatch pricing, and long-term investment decisions.

\section{A. Market Splitting Mechanism}

In recent scenario of India, power exchanges in the country are facing congestion due to limitation of power flows transmission corridor. Primarily, there is limitation in power flow in grid from surplus to deficit zone for optimize utilization of available transmission corridors considering social welfare with i.e. providing priority to higher buy bid prices in deficit areas and to lower sale bid prices in surplus areas. CERC approved the market Splitting mechanism in power exchange (IEX) and practically all energy exchanges around the world even Nordpool in Day-Ahead Markets (DAM) [13, 14].

Market splitting, mechanism is implicit process where auction and trade performed simultaneously through energy markets keeping allocation of transmission capacity according to buy/sale bids. The mechanism is further illustrated using a case with unconstrained formulation and constrained formulation of power flow in bidding area according to market clearing price (MCP) /area clearing price (ACP). Unconstrained condition give the market price value as Rs. 7991/ MWh in one hour, with the buy volume equivalent to the sale volume signify nil congestion. The power flow is according to block diagram given in figure 2(a). During the initiation of congestion, NLDC specifies the Congestion infected region in its exception report and its transmission capacity, constrained formulation is now implemented as per market splitting mechanism as shown in figure 2(b). The Constraint on the power flow to downstream deficit area from Surplus power region adjusted the area clearing prices (ACP) to equivalence of available transfer capability. The surplus area steps aim to reduction of quantity of expensive sellers with per volume price and steps of deficit power area aims to improve the quantity of relatively cheaper buyer finally leads to curtailment of power $[15,16]$. 

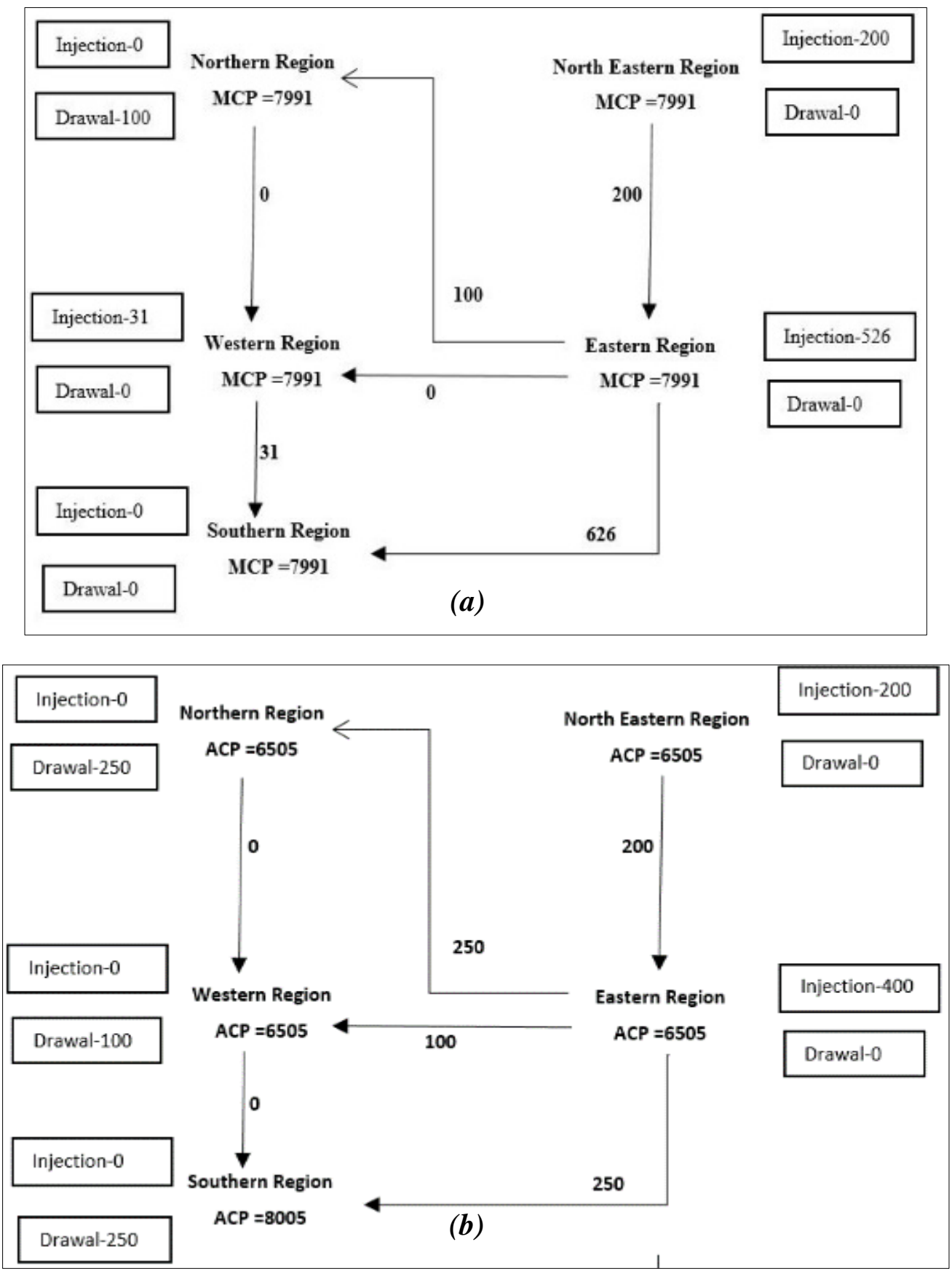

Fig. 2. Power flow in Transmission Corridor in (a) Unconstrained; (b) Constrained Condition

\section{Discussion AND Conclusions}

The issue of transmission congestion has created a huge trust deficit amongst consumers. There is a double whammy for the industry with no power availability from within the state or from outside it. The constrained formulation by splitting mechanism leads to introduction of new buyers were added due to decrease in price in surplus region, sellers conversion to buyers, curtailment in sellers/ buyers volume. There are some suggestion during congestion as listed below:

- Entire transmission capacity after allocation to long term customers should be utilized in the Day Ahead Market and left over if any could be utilized by the bilateral contracts.

- Alternatively, after allocation to long term customers, entire transmission capacity may be put on day ahead auction in a separate market which can be named as "Day Ahead Transmission Capacity Market". Exchange as well as participants in the bilateral deals can participate in such as segment and buy out the transmission capacity. Amount paid by the exchange for such transmission capacity can be apportioned by the Exchange on the participants on that date through a suitable mechanism. Funds generated through auction would be legitimately belonging to the owners of the transmission capacity who can utilize it for 
removing congestion under Regulatory supervision. This mechanism will not tinker with the existing Market Splitting methodology, which is serving us well by giving adequate price signals, as well as it will create level playing field between transactions on exchanges and bilateral transactions

- GNA is also a mechanism which can reduce congestion and bring transparency in corridor allocation.

- Risk hedging products like PTRS should be introduced in India to reduce the transmission price risk.

- The transmission planning criteria which is made by CEA is only considering long term, it should be made according to short term also.

\section{REFERENCES}

[1] Prabhakar Karthikeyan S, Jacob Raglend I, Kothari DP. A review on market power in deregulated electricity market. Int J Electr Power Energy Syst 2013;48:139-47. doi:10.1016/j.ijepes.2012.11.024.

[2] Alomoush MI. Performance indices to measure and compare system utilization and congestion severity of different dispatch scenarios. Electr Power Syst Res 2005;74:223-30. doi:10.1016/j.epsr.2004.10.012.

[3] Lo KL, Yuen YS, Snider LA. Congestion management in deregulated electricity markets. DRPT2000 Int Conf Electr Util Deregul Restruct Power Technol Proc (Cat No00EX382) 2000.

[4] Pan J, Teklu Y, Rahman S, Jun K. Review of usage-based transmission cost allocation methods under open access. IEEE Trans Power Syst 2000;15:1218-24. doi:10.1109/59.898093.

[5] Installed_capacity 2016. http://www.cea.nic.in/reports/monthly/installedcapacity/2016/installed_capacity-08.pdf (accessed October 26, 2016).

[6] Inter Regional Transmission Capacitytle 2016. http://powermin.nic.in/en/content/inter-regional-transmission-capacity (accessed February 5, 2017).

[7] Pillay A, Prabhakar Karthikeyan S, Kothari DP. Congestion management in power systems - A review. Int J Electr Power Energy Syst 2015;70:83-90. doi:10.1016/j.ijepes.2015.01.022.

[8] Kristiansen T. Congestion management, transmission pricing and area price hedging in the nordic region. Int J Electr Power Energy Syst 2004;26:685-95. doi:10.1016/j.ijepes.2004.05.004.

[9] Xiao Y, Song YH, Liu CC, Sun YZ. Available transfer capability enhancement using FACTS devices. IEEE Trans Power Syst 2003;18:305-12. doi:10.1109/TPWRS.2002.807073.

[10] Hingorani NG, Gyugyi L. Understanding FACTS: concepts and technology of flexible AC transmission systems. Order A J Theory Ordered Sets Its Appl 2000:432. doi:10.1109/9780470546802.

[11] David AK. Dispatch methodologies for open access transmission systems. IEEE Trans Power Syst 1998;13:46-53. doi:10.1109/59.651612.

[12] Mukherjee MS, Dhingra T, Sengupta A. Electricity Act 2003 : Review of Select Indicators 2006:212-29.

[13] Sinha P, Mathur K. Empirical Analysis of Developments in the Day Ahead Electricity Markets in India 2016.

[14] Tripathi MM, Pandey AK, Chandra D. Power system restructuring models in the Indian context. Electr J 2016;29:22-7. doi:10.1016/j.tej.2016.05.002.

[15] Indian Energy Exchange n.d. https://www.iexindia.com/ (accessed February 5, 2017).

[16] Management of Risk in the DAM, TAM and REC Market n.d. https://www.iexindia.com/faqs.aspx?id=31\&mid=1 (accessed February $5,2017)$ 